\title{
Assessing Water- Based Recreational Activities to Project Beach Ecotourism Potentials in Kisumu County
}

\author{
Okungu Jared Ouma ${ }^{1}$, Patrick O. Hayombe ${ }^{2}$ and Stephen G. Agong ${ }^{3}$ \\ ${ }^{I}$ PhD student and researcher, Jaramogi Oginga Odinga University of Science and Technology; \\ ${ }^{2}$ Supervisor and Dean, School of Spatial Planning and Natural Resources Management, (PhD); Jaramogi \\ Oginga Odinga University of Science and Technology \\ ${ }^{3}$ Vice Chancellor (Professor), Jaramogi Oginga Odinga University of Science and Technology
}

\begin{abstract}
This paper presents discussions on observed scenarios that characterize water-based recreational activities with an aim of laying grounds for appreciating relationships that enhance or hamper ecotourism development in Lake Victoria, Kisumu County. The study was premised from an argument that lake water resources demonstrate prospects for activities like swimming, boating, sunbathing, skiing, recreational fishing and visual amenities among others. The study was conducted through observations and confirmatory follow up queries from relevant stakeholders along Lake Victoria from Asat, Ogal, Usoma and Lwangni beaches of Lake Victoria. The main objective was to examine existing trends of water-based activities in relation to ecotourism and envisage potentials of each beach water front for recreation in Kisumu County. Thus, this paper presents results of a systematic synthesis of interactions between lake (surface) water and outdoor recreation, a significant socioeconomic subsystem. The study maps out characteristics of accessible water front areas, popularly known as beaches, for their ecological sensitivity and ascertains the possibility of the sites to be planned or augmented to facilitate ecotourism development. Findings reveal the spatial potential of the sites but with gaps that intimidate possible popularity of ecotourism industry due to intentional human activities, negligence and perceptions. The existing technical and scientific knowledge on Lake Victoria Basin has been boosted by this study; hence, results and recommendations potentially enable academic institutions, development agencies and Kisumu County Government to seriously begin ecotourism development, which has remained behind most developed nations.
\end{abstract}

Key Words: Water-Based, Recreational Activities, Beach Ecotourism, Ecotourism Potential

\section{Introduction}

Water resources demonstrate a fundamental home to biodiversity and attractive features to recreationists in many villages, towns and cities around the world (Keys, et al, 2012). They present potentials for water-dependent recreational activities like swimming, boating, sunbathing, skiing, recreational fishing and visual amenities (Godbey, 2009). Water-dependent ecotourism in the developed nations like the Caribbean islands, the United States and the Middle East are appropriately exploited to the advantage of nature conservation and economic gains through suitable policies, plans, management systems and budgets. However, this only compares in contrast with developing nations, some of which are endowed with water resources in the form of lakes and rivers (Ngunyi, 2009).

The Great lakes of Canada are among the world's largest freshwater bodies that are useful for recreation by more than 30 million people (Wong, et al, 2009). There are more than 1,300 beaches along these Great Lakes that are involved in recreational ecotourism, though they experience risks of contamination by domestic pollution (Edge \& Hill, 2007). In India, Lake Chilika, the largest coastal water lagoon exhibits a unique ecosystem with fresh, brackish and marine water zones supporting a characteristic biodiversity (UNEP, 2009). The ecosystem services provided by the lake include recreational ecotourism which is widely practiced by the local community. However, there are challenges of degradation at various adverse levels due to pollution and mismanagement.

In developing nations beaches have yielded little development in ecotourism sector, yet water based ecological resources they are endowed with are eminently abundant for potential enhancement of recreational activities (UNEP, 2012). According to UNEP (2009) lack of proper planning, adequate management coupled with human activities have resulted in water resources and ecosystem degradation within beach environs. This confirms the negative impacts of non-sustainable water use and non-exploitation of potential beach recreational areas in Africa.

In Kenya, tourism activities only thrive in the coastal city of Mombasa, and in established peripheries, which nevertheless, do not subscribe to ecotourism principles (Ngunyi, 2009). For a long time tourism been exclusively centered on three geographical areas namely, coastal area for beach tourism, Nairobi for business or conferences and Maasai land for game viewing and Safaris (Ngunyi, 2009). Studies have concentrated on 
conservation of aquatic species and economic sustainability of the fishing community around the Lake Victoria within the east African countries of Kenya, Uganda and Tanzania but with little focus in ecotourism (WASPA, 2013). Yet, with the existence of agencies advocating for environmental conservation matters in Kisumu and its environs, little traces of recreational ecotourism activities can be accounted for. Kisumu Local Interaction Platform (KLIP) (2013) also notes that potential of tourism in Kisumu is yet to be exploited.

Exploitation of water resource for beach recreation can be taken advantage of as an ecotourism product if it is preserved and utilized appropriately. But Kisumu County has experienced difficulty in engaging in waterbased ecotourism for as long as the industry evolved. Although research studies have collected ecotourism data in Lake Victoria, the same have limitations for use to map out water-based recreational activities. This difficulty is compounded by the fact that just one or two sites where the studies have been concentrated cannot scientifically be used to extrapolate findings for the more than 25 beach sites that form the study population.

As such, the accuracy of any data that can be used for water based recreation in Lake Victoria is generally uncertain. This backdrop persists given that potential areas are either not definite, have been avoided, ignored or abandoned. Nevertheless, there exist several identifiable ecologically sensitive areas within front sites of Lake Victoria that retain the potential for exploitation for ecotourism attraction (EAC, 2011). This informs the rationale of assessing water-based recreational activities to project beach ecotourism potentials in Kisumu County. The rationale behind this study is that Kisumu should not remain dormant on gainful recreation (waterbased) with the kind of fresh water resource it has; with such a resources local communities should not live in unwarranted social livelihood (low); and Local and foreign visitors should not be begged to express eagerness for water-based recreational activities but should themselves seek a chance to participate in recreational activities.

The study was conducted in front sites of Lake Victoria in Kisumu County, which has 25 accessible beaches. With a shoreline of 3,440 km, Lake Victoria is the second largest fresh water lake in Africa. It has an average depth of $40 \mathrm{~m}$, maximum depth of $80 \mathrm{~m}$ and a water volume of $2,750 \mathrm{~km}^{3}$ (EAC, 2011). The lake is situated at an altitude of $1,134 \mathrm{~m}$ above the sea level. It lies between latitudes $00^{\circ} 30^{\prime} \mathrm{N}$ and $355 \mathrm{~km}$ from west to east between longitudes $31^{\circ} 37^{\prime}$ and $34^{\circ} 53^{\prime} \mathrm{E}$.

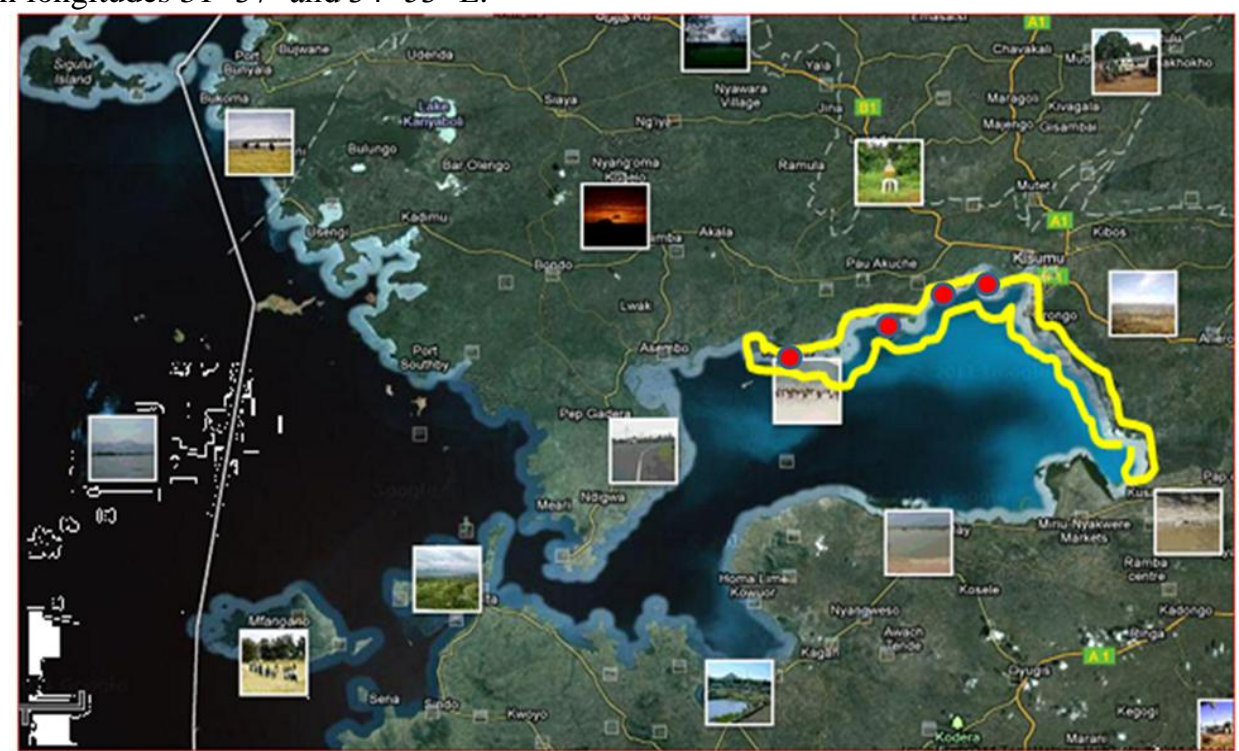

Figure 1: Map of Lake Victoria, Kisumu - Kenyan, showing study area (Source: KLIP, 2013)

\section{Ecotourism and Recreational Beach Activities}

\section{Review Of Literature}

Ecotourism involves travel to natural destinations with the aim of minimizing negative impacts; building environmental awareness; providing direct financial benefits for conservation; providing financial benefits and employment for local people; respecting local culture; and supporting human rights and democratic movements (Fennell, 2003). Recreation that is associated with leisure and tourism with the view of conserving natural resources is, therefore, ecotourism. The goal of ecotourism is a symbiotic relationship between local communities, tourism and biodiversity conservation.

Recreation in beach waters entail boating, swimming, windsurfing, waterskiing, camping, sunbathing, white water sports, scuba diving, and dinghy sailing (Canadian Council of Ministers of the Environment, 2008). These leisure or recreational activities involve body contact with water at different levels hence, but adequate literature on environmental and ecological conditions under which the water- based activities would be participated in by the local or foreign recreationists has not been offered. 
Brown, Soaemalelagi \& Wasco, (2003) suggest that the first step in building an ecotourism industry is to identify and highlight the key ecotourism locations, activities, experiences, perceptions, opportunities and relevant projects. This is supported by the Tanzanian National Tourism Policy, whose ecotourism strategies include designing environmentally friendly tourism programs and putting in place mechanisms that will ensure that tourist activities respect use of biodiversity, wildlife, beaches and other naturally occurring phenomena of esthetic value.

\section{Perceptions, Beach Activities and Quality of Beach Environments}

UNEP, (2009) suggests that in many situations, changes subjected to surface water environments negatively alter surrounding and downstream landscape of ecosystem. Pergams and Zaradic (2008) argued that all major lines of evidence point to a general and fundamental shift away from people's participation in naturebased recreation. The mental and physical health benefits to humans of direct environmental contact are quite well-documented (Park, O'Brien, Roe, Thompson \& Mitchell, 2011; Dustin, Bricker \& Schwab, 2010; Hartig, Kaiser \& Strumse, 2007). Pendleton et al (2000), observe that people's recreation behavior is assumed to be indirectly affected by water quality, via the individuals' formulations of perceptions about their environment.

KLIP (2013) demonstrates that a change of attitude is needed among community members and that the community should have knowledge of their resources. This is imperative because local community members posses the ability to directly affect quality of their natural environment through individual behaviors, which may depend on people's perceptions of the environment. But Pendleton, Martin \& Webster, (2000) argues that community participation, in many occasions is affected by perceptions which might influence efforts and eventual actions towards recreational areas and associated activities. Hayombe Hayombe, Agong', Nystrom, Mossberg, Malbert \& Odede, (2012) recommends that local community's perceptions on significant sustainability factors for ecotourism transformation are critical at the initiation of the ecotourism project.

Hayombe, et al, (2012) identifies willingness to participate or local community intention and readiness to engage in ecotourism as a sustainability factor for ecotourism transformation. But this willingness is pegged on status of recreational waters, hence, attracting the public's interest to ensure their participation in recreational activities, according to Bahri, (2012), is essential in providing better explanations about the extent to which physical, ecological and environmental status of beaches influence participation. Because an individual's perception of environmental quality and risk may affect their behavior, (Zhang \& Lei, 2012; Honey, 2008), diverse perceptions among beachgoers may result in unique recreation patterns at any particular beach. This implies that to properly manage beaches it is necessary to understand people's motivations for using the beach and the ways in which perceptions of risk and the environment influence these motivations.

The above literature remain suggestions and assumptions as they do not demonstrate practical realities of the extents to which beach environmental quality affects participation in recreational activities in Lake Victoria, Kisumu County. Hence, assessment of such extents was considered by this study as a fundamental background to demonstrating relationships that exist amongst variables. This study, therefore, constructs information that enables interaction of its findings with other variables like water quality and participation levels to as to determine opportunities of recreational ecotourism in water resources within beach environments of Kisumu County, as projected in figure 2.

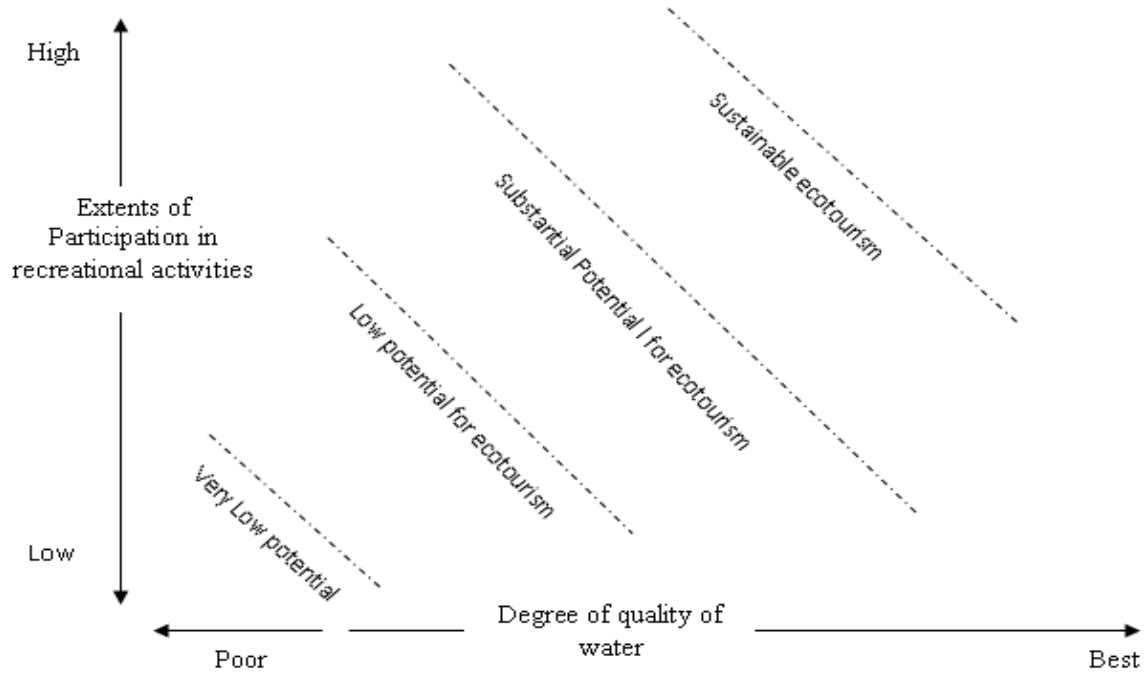

Figure 2: A conceptual projection of interaction with variables 


\section{Theoretical framework:}

Basing on Ruane's (2005) assertion that Concepts work their way into research via theory, the study is guided by Systems Environment Theory (Tamas, 2000) and the Theory of Planed Behaviour (Ajzen, 1991).

\section{System Environments Theory}

The first theory that this study was based on is the Systems Environments Theory by Tamas (2000). It illustrates key concerns in sustainable development, such as understanding dynamics of inter-group relationships, and considering changes involved in planning development activities that can be understood and described. The theory exemplifies that several environments form the context within which any system exists, and energy or influence might be able to flow across the boundary from one environment to any other to alter the balance of any part of the system.

The boundaries between these systems are not discrete, and Byrne (2001) identifies "nested interpenetrating systems", which intersect and interact, with influence flowing in many directions as policy is developed and enacted. The interactions between people and environment in these different systems are constantly evolving (Healey, 2007; Sanderson, 2000).

This theory can be considered relevant in this study as further discussed below:

- The Deeper Internal Environment of which the System is Unaware - i.e, a possible internal desire among a community, sector marketers and ecotourists to exploit and enjoy the available natural resources that offer attraction as a product for ecotourism. Because the society and authorities are not aware (or adequately sensitized) of potentials for such exploitation, this study sought to map out these sites and declare their potentiality for exploitation.

- The system under consideration, and the internal environment of which it is aware - i.e, the direct and indirect water and environmental quality status that the community is aware of, and that affect attraction to recreational sites due to possible health fears or experiences.

- The system's External Environment of which there is some awareness - there could exist some circumstances that are not within matters defined by the immediate problem, but those that are understood by people affected. The awareness is stipulated as "some" to mean inadequate or amorphous phenomena, but which ought to be explored for knowledge and solution. In respect of this study, it was imperative to put the society into the knowledge of the risks and benefits of beach waters that can be exploited for recreational ecotourism.

- The system's distant external environment of which it is not aware - i.e, changes in recreational and water environments which the society might only understand when research is initiated and results disseminated. In this study context planning and conservation frameworks are steps that were aimed at realization of opportunities of recreational ecotourism in water resources within urban environments.

\section{Theory of planed behaviour}

Secondly, the study's argument can be based on the Theory of Planed Behaviour by Ajzen (1991). The theory suggests that one influencing factor is people's knowledge. It is commonly assumed that what people know directly influences how environmentally friendly their behaviour is, but other theories and findings indicate that knowledge only indirectly influences behaviour (Kaiser and Fuhrer, 2003). Geller (1995) suggest that knowledge influences behaviour via attitudes. Other authors suggest that knowledge acts via perceived behavioural control of behaviour (De Young 2000).

In their very profound study of knowledge, Frick, Kaiser \& Wilson, (2004) found that action-related knowledge and effectiveness knowledge have a direct effect on behaviour, but system knowledge has only a mediated effect via the other two knowledge types. This model is, therefore useful in predicting recreation behaviour, hence, is used as a theoretical basis to predict ecologically responsible recreation activities on the basis of attitudes, motivations, and other factors. Hence, the two theories recognize the fact that a central issue that adds complexity to outdoor recreation assessments involves the need to characterize how recreation is "produced."

\section{Materials And Methods}

The study was conducted in beaches along the shoreline of Lake Victoria, Kisumu County. The following is the sample frame from which the 6 study sites were chosen: (1) Orogo, (2) Bao, (3) Asat, (4) Ugwe Ochok (5) Ogenya, (6) Kaloka, (7) Rare, (8) Kadibo, (9) Kusa, (10) Ogal, (11) Kaloleni, (12) Mawembe, (13) Kobudho, (14) Paga, (15) Othany, (16) Usare, (17) Usoma, (18) Kichinjio(19) Lwang'ni, (20) Dunga, (21) Nyandiwa, (22) Nyamware, (23) Oseth, (24) Nduru, and (25) Sangorota. Because of the spatial diversity of the beach areas, 4 beaches were determined to be adequate to carry out the study through observation. 
From a systematic arrangement of the 25 accessible sites in Kisumu County, the third one was randomly picked from the East towards West and every subsequent in the frame $4^{\text {th }}$ was picked resulting to Asat, Ogal, Usoma and Lwang'ni, beaches as shows in figure 3 .

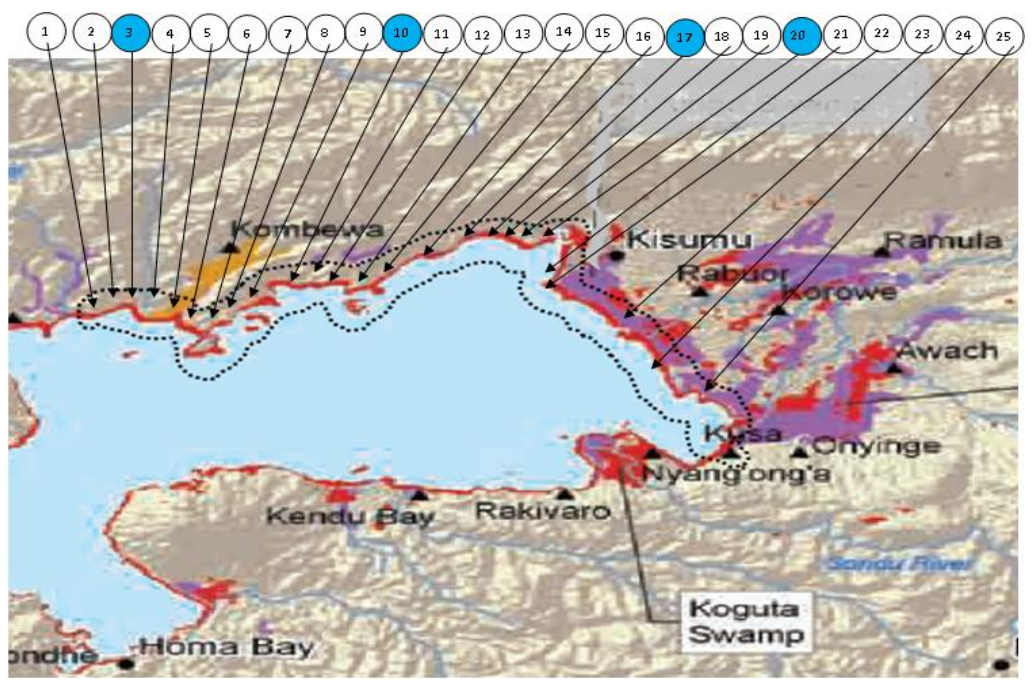

Figure 3: Map of Lake Victoria, singling out study sites

\section{Data collection process \\ Introduction}

The study involved observation of natural and artificial features, behaviours, practices and water-based recreational activities by people at each of the beach sites. A schedule of activities was made for the study execution by a research team of 5, including the lead researcher. The team visited each of the 4 sites for 3 days from 9.00 am to $5.00 \mathrm{pm}$ each day and conducted consultative observations through checklists. Data collected in this manner included natural features, facilitative infrastructure, leisure activities, observable water and environmental quality status, and daily human activities and behaviours within each site area. Confirmatory clarifications on the observations were made with Beach Management Officials to ensure that the recorded data were accurate. Each research day culminated to a closing meeting to corroborate information gathered by the researchers and those that were offered by the beach management.

\section{Natural Features}

The study considered that natural features were important in order to enable an understanding of ecological sensitivity of each of the study site so as to priorities their enhancement for ecotourism development. The features observed and recorded include the presence or absence of dry land, vegetative land, or wetland. The extents of these characteristics were coded with different texture blocks to signify degrees of dryness, vegetative or wet nature of the beach lands. The same was scored into percentages so that it would easily advance an interpretation of the occurrence of these characteristics.

\section{Facilitative infrastructure}

Constructed features were deemed appropriate for the study to consider because local and visiting ecotourists, as in other developed tourist destinations, would require them to facilitate the ecotourism experience at the beaches. These features included tarmac or murram roads to the beach sites, boat landing docks or wharfs, and beach hotel or rest rooms/shades. The presence, absence and nature of occurrence of these features were recorded in checklists which would provide easy comparison across all selected study sites.

\section{Leisure (recreational) Activities}

The study observed and recorded incidences of leisure (recreational) activities in their different enormities and time of occurrence. These activities included leisure boating, leisure fishing, camping, swimming, canoeing, sunbathing, wind surfing and water-skiing. On a similar note, in order to understand the general engagement in water based activities, enquiries were made on extents of non-recreational activities like commercial fishing and boat transport from Beach Management officials to understand the frequency with which there activities are ongoing in each of the sites. The number of times was recorded in a checklist for the time durations of between $8.00 \mathrm{am}$ to $6 \mathrm{pm}$. 


\section{Observable water status}

The considered assumption by literature that levels of recreational activities could be influenced by water and environmental quality status at the beach sites, prompted inclusion of various observablzale quality and aesthetic characteristics of the beach environments. Hence, the observed variables included intensity of coloured water, suspended matter on water, settleable solids at shore, oil films and foams, decayed organic matter at shore and presence of algae. For a distance of $6 \mathrm{~m}$ from the shore line into the lake, colour intensity of the water was compared with a provided resolution code in percentages and a percentage was scored per beach, because each beach had a uniformity in water colouring. On the same order, the magnitude of suspended solids on the water of water was coded into percentages. On the other hand, the volume of settleable solids was approximated in $\mathrm{m}^{3}$ against all solids that were found at the beach waters within $6 \mathrm{~m}$ from the shore water. This was done by measuring the depths of the sediments at the sites. The spatial spread area of oil films and foams were approximated in $\mathrm{m}^{2}$ within the same $6 \mathrm{~m}$ distance into the lake and a percentage spread was developed and considered as the coverage extent. The occurrence of decayed organic matter was likewise approximated as was settleable solids. Finally the presence of algae was determined as was oil films and foams.

\section{Daily human activities and behaviours within the area}

In order to establish possible pressures posed by daily human activities on the observable status of the water observations were made on animal watering, liquid waste disposal, organic waste disposal, nonbiodegradable waste disposal, car washing, and clothes washing \& bathing at shore. These characteristics were observed and recorded and their extents were merely discussed because it was difficult to provide scores of their magnitudes. This is because interviews with locals indicate periodic fluctuations in magnitude.

\section{The Presence of the lake water mass}

\section{Results And Discussions}

The presence of the large water mass, the Lake Victoria in Kisumu County avails front sites of the lake is in itself a greater potential for exploitation as an ecotourism destination. Whether or not this water body is exploited to expected standards, it is evident that since in various developed countries such water bides exhibit ecological sensitivity, and providing natural features that qualify for ecotourism attraction, only hindering factors could be studied. All the chosen sites are found along the lake shorelines.

\section{Natural Features}

Observation results coded with different textured resolutions indicate 95\% dry land for Asat beach, and $80 \%, 80 \%$ and $85 \%$ for Ogal, Usoma and Lwangni beaches respectively. This implies that the beaches can accommodate recreation activities since several of such activities are not favored by wetland situations. This result is presented in Figure 4.

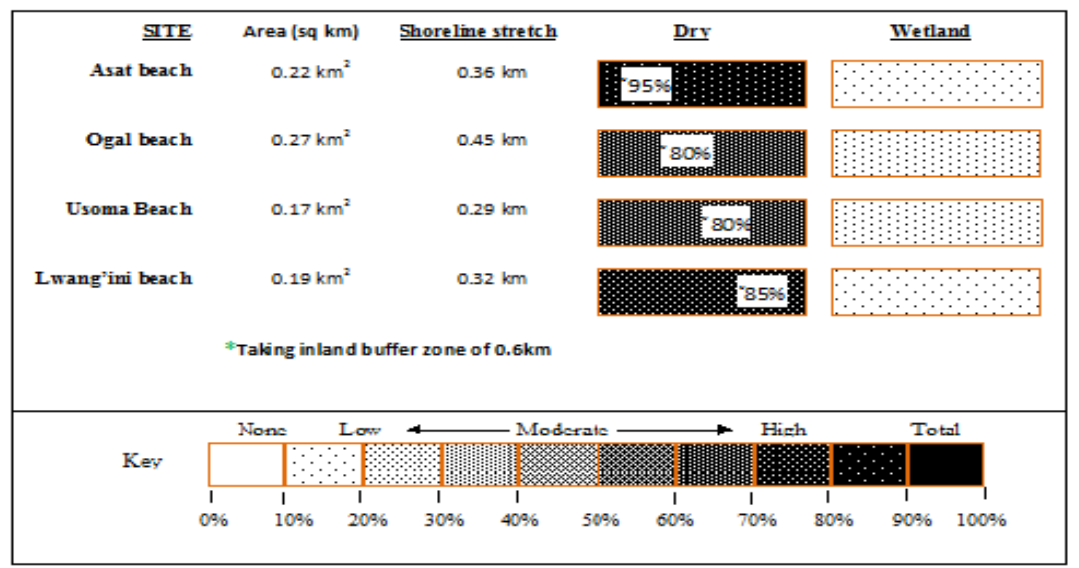

Figure 4: Illustration of ecologically sensitive features - land and vegetation in surrounding

The combination of majorly drylands and minor spatial spaces of wetlands exhibit substantial features of ecological diversity, which may attract water-related ecotourism for those that like to have experiences with birds, frogs, mudfish and diverse species of plants. Presence of water hyacinth was tricky to assess since they exhibit an expedience of irregular fluctuations. 
Assessing Water-Based Recreational Activities to Project Beach Ecotourism Potentials in ....

\section{Facilitative infrastructure}

The infrastructure that would enable access and comfort of the recreationists were assessed and results indicate that out of the listed parameters, only Dry Murram road and traditional resting shades were available. Though other facilities existed, they were not considered since they were meant for domestic and commercial activities and of ecotourism.

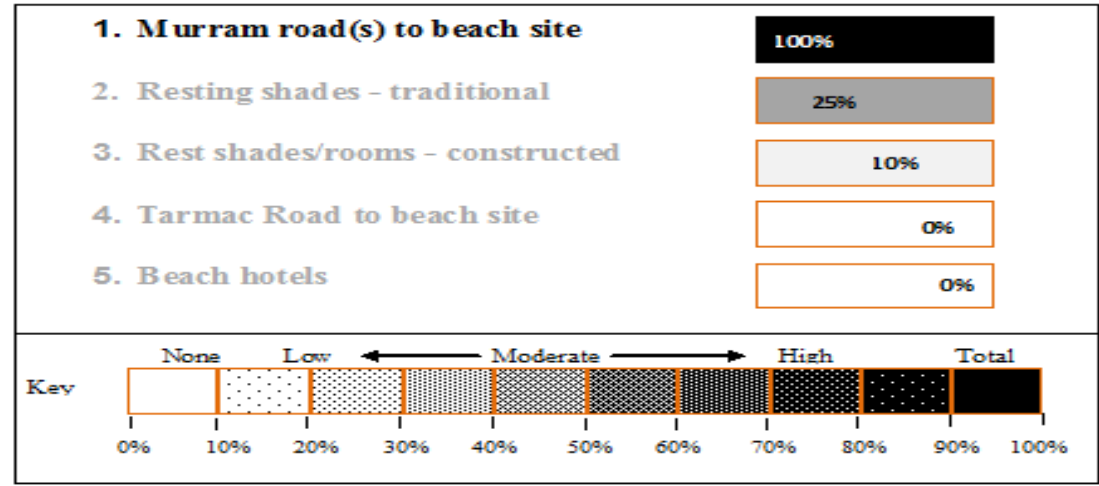

Figure 5: Facilitative Infrastructure at the Beach sites

The absence of tarmac roads, constructed rest shades and hotels does not, however, signify lack of potentiality. This is because, though, these facilities would enhance visitor perception of ecotourism destinations, their absence aren't within the ecotourism criteria of those things that must be available.

\section{Leisure (recreational) Activities}

\section{Fishing by boats}

From the observed results indicate a larger extents of commercial fishing compared to leisure fishing. However, the economic benefit for the leisure fishing could not be established since the activity was not organized with ecotourism orientation. The results on this observation are as indicated in figure 6.

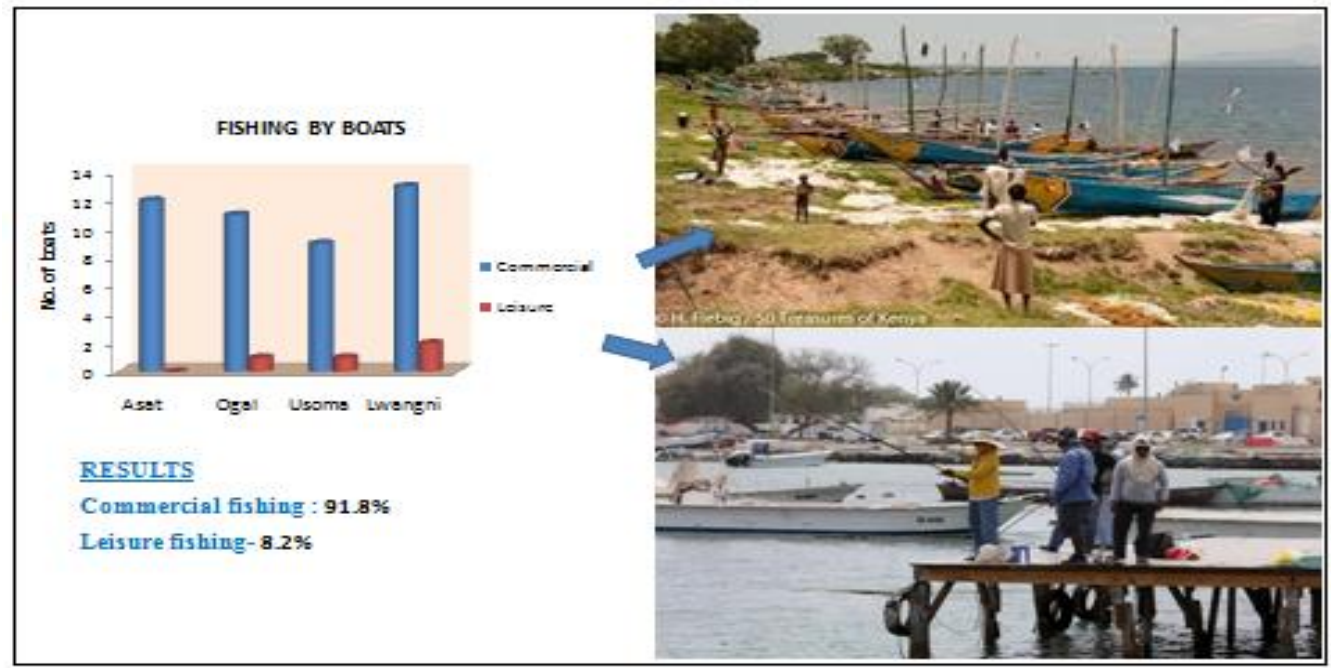

Figure 6: Comparison between commercial and leisure fishing in Lake Victoria

In total $91.8 \%$ of the vessels at the beaches were used for commercial fishing while $8.2 \%$ were for leisure fishing. Not captured in this report is a number of fishing activities that occurred along the shorelines by people doing so while standing. Another aspect of fishing activity at the beaches was fishing competitions (as sports), which were noted as a recent innovation. Competitors were most often professional fishermen who are supported by commercial endorsements.

\section{Transport by boats}

The other two kinds of water-based activities observed were boating for transport and boating for leisure. Data observed on these activities were grouped during analysis for comparison purposes. However, the analysis did not consider whether the boats used were motorboats or canoes. The results are illustrated in figure 7 


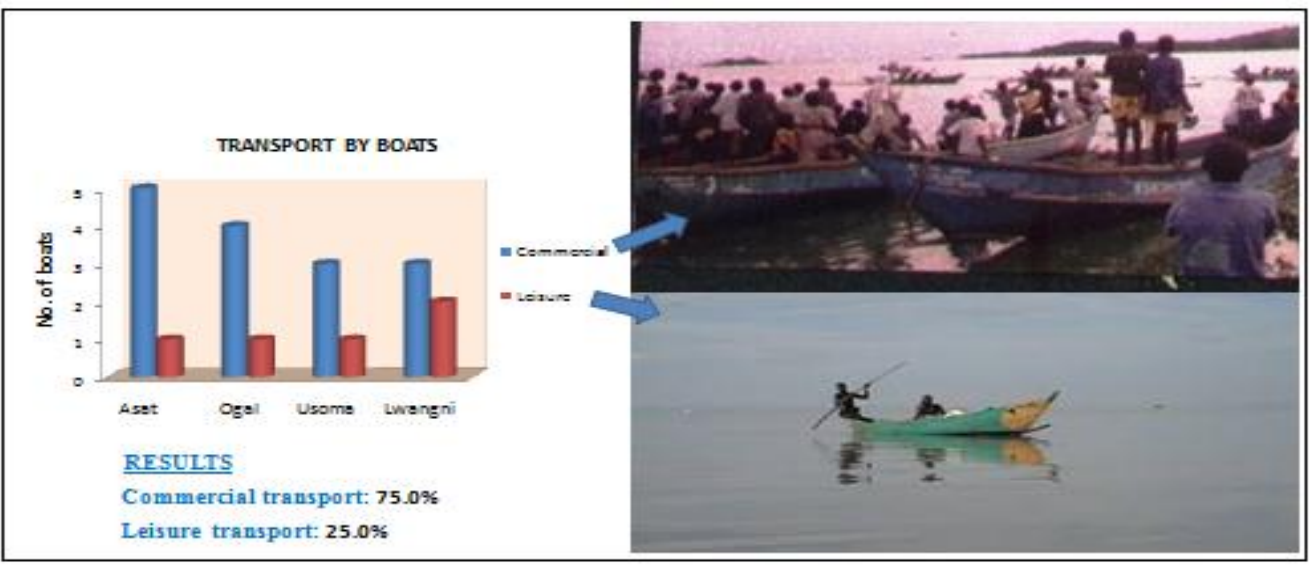

Figure 7: Comparison of boating activities for transport and leisure purposes

At various rates, water-based activities on transport and leisure riding occurred at each of the beaches, hence, the number of times that boats left or docked at the beaches were captured from existing literature. This literature was supported by oral recounts from Beach Management Officials.

\section{Observable water quality status}

The aesthetic or sanitary status of the beach sites were important to consider since they would probably influence behaviors and perceptions of individuals while choosing to participate in water-based recreational activities outlined above. The observations were made during rainy season, but there is a possibility of slight variation if a dry season was considered for observation. The observed variables in the case of rainy season were presented in a scale of textured blocks with various resolutions representing magnitudes (percentages) as shown in figure 8 .

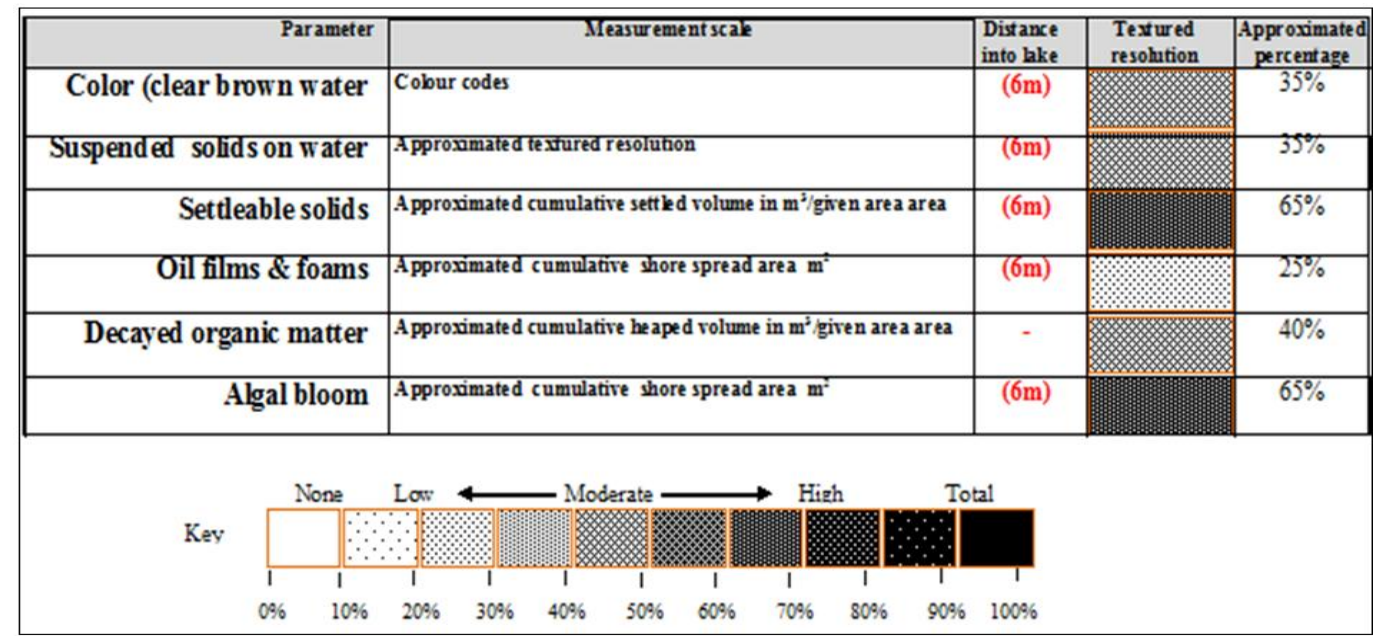

Figure 8: Presentation of magnitudes of sanitation and aesthetic status at the beaches

Results obtained show variations of occurrence of several variables. Each of the observed beaches had average coloured water at $(35 \%)$, suspended solids $(35 \%)$, settleable solids $(65 \%)$, oil films and foams $(25 \%)$, decayed organic matter $(40 \%)$ and algal bloom at $65 \%$.

\section{Daily human activities and behaviours within the area}

The study deemed important to observe activities ongoing along the shorelines within the beach areas. Important to note is the fact that in all the beaches, at least there are residents living within the beach buffer areas, though the Kenya Government claims ownership of buffer regions of at least 300m from the shoreline. The residential areas comprise rental houses, small shops, eating places and fish racks and small stores.

This was in order to deduce possible reasons for the status illustrated in figure 8 . The researchers experienced a lot of fluctuations in these behaviors, hence it was agreed that their occurrences be discussed rather than being presented graphically. All the activities practically occurred as expected, for instance, animal watering was done at all the shores except Kichinjio. Several animals including cows, goats, sheep and donkeys 
were led to different sections of the lake within the beaches and were made to drink water at midday hours. The animals left the places full of sanitation lapse. These contributed to the presence of decayed organic matter and definitely the algal bloom (although this was not scientifically confirmed).

At all times women who bought fish from the just laded boats washed them and disposed their remains back to the beach water. The fish cleaning sites disturbed the entire beach with foul smell, scavenger birds, wading dogs and flies, which are usually small in area. In all the beaches, except Oseth and Paga, Car Washing was another business observed to be carried out by the locals. Cars of different capacities were dragged to the shores and washed at different times of the day. The waste waster from car-wash was then led to drain into the lake. This practice was supposedly responsible for the presence of oil films and foam as reported in figure 7. All the study areas exhibited the acts of liquid waste disposal at the shore waters. Small local businesses like hotels, butcheries and people living within the areas disposed their kitchen wastes by pouring them in open channels that drain directly into the lake. Other open channels from beach upstream areas also drained into the beaches, supposedly inletting agricultural and domestic wastes.

Heaps of solid wastes were also seen in each of the beaches at eyesore conditions and undesignated areas. The heaps combined biodegradable and non-biodegradable materials of undefined quantities. These activities generally contributed to undesirable hygiene and sanitation condition of the study sites, although the same might be dealt with through policy formulation and planning. However, this study is conscious of the fact that there could exist some sewer and industrial waste outfalls at certain other sites that were not studied because they were not accessible.

\section{Conclusions}

The water mass of Lake Victoria is a succinct indicator of the potentiality of Kisumu County in producing and supplying ecotourism products. Water based activities like in most other developed nations can be harnessed from their low levels into attractive movers of interesting recreational ventures for both local and foreign recreationists. The presence of various activities along the beaches in Kisumu Count and the low levels of uptake of ecotourism ventures along the water fronts prompted this research, which advances conclusions based on the themes: natural features, facilitative infrastructure, leisure and the d daily human activities and behaviours within the study area.

The presence of the natural features, though not immediately recognised by the locals as being of ecological importance, prove good reasons for further preservation for ecotourism promotion. In the local beach villages wetlands are generally considered a wasted land area by local people because they cannot farm, build or graze animals in them. But ecologists consider them essential for conservation of biodiversity. For ecotourism purposes, the existence of the wetlands does not hinder water-based recreational activities from being interesting. Hence no amount of dry land needs to be converted into wet or vice versa for it to be relevant for ecotourism.

The diversity seen in the nature of the potential recreational sites calls for categorizing the sites into those that support certain activities and get branded as such. For instance, while all the sites are suitable for boating and leisure fishing, swimming is not feasible in areas with substantial wetlands like Paga and Oseth. Sunbathing and camping are also viable in all the sites but remain dependent on the presence of a few artificial facilities to be added at the sites. The concept of ecotourism does not demand engineered infrastructure for a site to quality, but rather the ecological sensitivity of the area plus accessibility. The Murram roads leading to the study sites plus the traditional resting shades already qualify them for ecotourism venture. In fact attempts to modernize the infrastructure might sweep away the concept of ecotourism. Hence on this category all the sites are considered adequate enough to receive ecotourists.

Interestingly, local people who engage in leisure activities are not aware that they are actually local ecotourists. The only difference is that these activities might not have sufficient economic gains. Commercialization of the leisure activities like boat riding and fishing competitions are rarely carried out. The beaches of Lake Victoria, Kisumu County do not have the essential enthusiasm from locals that can also attract visitors who are ecotourists. This is because foreigners are always careful of their health and the status of the beach waters and their surroundings are health-threatening for possible bodily contact with contaminated water. Recreational fishing competitions (tournaments) can be modeled as an ecotourism activity in all beaches.

The results of the status of the environment and the water remained intimidating for ecotourism venture at the studied beach sites. It is recognizable that some of the wastes disposed at the beach waters are beyond the local population, for instance those that emanate from upstream ends. Yet a greater percentage of the wastes are generated and disposed of right at the waters. 


\section{Recommendations}

Based on the findings and conclusions made the following recommendations are necessary for consideration by all stakeholders of ecotourism, water resources and beach environment:

- Preserve features that occur naturally and that are ecologically sensitive at every beach and protect them from destruction or overexploitation.

- Promote an integrated resource management framework for upstream activities, beach area residents and beach water users so that each category of these stakeholders has a clear understanding of the rationale for ecotourism.

- Introduce appropriate hygiene and sanitary behaviour among people living at beaches, and sensitize them for behaviour change within every beach settlement regardless of the magnitude of recreational activities or ecotourism experiences. This includes but not limited to beach cleaning activities and proper waste disposal.

- Encourage fishing and boating competitions. Other unpopular ventures like sunbathing and camping should also be encourage and a few structural facilities should be made in place for them.

- Because swimming is not viable in every beach, it is important that appropriate sites at selected beaches, branded and facilitated with swimming floats and guides.

\section{References}

[1]. Ajzen, I., (1991): The theory of planned behaviour. Organ. Behav. Hum. Decis. Process. 50: 179-211.

[2]. Ajzen, I.; Driver, B.L., (1992): Applications of the theory of planned behaviour to leisure choice. J. Leis. Res. 24: 297-316.

[3]. Bahri, A (2012): Integrated urban Water Management. Glbal Water Partnership Technical Committee Background Papers No. 16

[4]. Brown, Soaemalelagi \& Wasco (2003); Ecotorism Plan Proposal for American Saoa, ECOCLUB.com E-Paper Series, Nr. 5.

[5]. Byrne, D. (2001): 'Complexity science and transformation in social policy', Social Issues, Vol. 1, No. 2, Obtained through the internet: http:/www.whb.co.uk/ socialissues/ tb.htm (Accessed 24 December 2013)

[6]. De Young, R., (2000): Expanding and evaluating motives for environmentally responsible behaviour. J. Soc. Issues 56: $509-526$.

[7]. Dustin, D.L., Bricker, K.S., \& Schwab, K.A. (2010): People and nature: toward an ecological model of health promotion. Leisure Sciences, 32, 3 - 14

[8]. EAC, (2011): A study on aquatic biodiversity in the Lake Victoria Basin, Kenya: ACTS Press, Afrian Centre for Technology Studies, Lake Victoria Basin Commission.

[9]. Edge, T.A., \& Hill, S. (2005): Multiple lines of evidence to identify the sources of fecal pollution at a freshwater beach in Hamilton Harbour, Lake Ontario. Water Res. 41.

[10]. Fennell, D.A. (2003): In D.A. Fennell and R.K. Dowling (Eds.), Ecotourism Policy and Planning. CABI Publishing, Ontario.

[11]. Frick, J., Kaiser, F.G.; Wilson, M., (2004): Environmental knowledge and conservation behaviour: Exploring prevalence and structure in a representative sample. Pers. Individ. Differ. 37: 1597-1613.

[12]. Geller, E.S., (1995): Actively sharing for the environment: An integration of behaviorism and humanism. Environ. Behav. 27: 184195.

[13]. Godbey, G. (2009): Outdoor recreation, health, and wellness: understanding and enhancing the relationship (RFF DP 09-21). Washington, D.C.: Resources for the Future.

[14]. Hartig, T., Kaiser, F. G., \& Strumse, E. (2007): Psychological restoration in nature as a source of motivation for ecological behaviour. Environmental Conservation, 34, 291-299.

[15]. Hayombe, P.O., Agong', S.G., Nystrom, M., Mossberg, L., \& Malbert, B., and Odede, F. (2012): Up-scaling ecotourism in Kisumu city and its environs: Local community perspective.

[16]. Healey, P. (2007) Urban Complexity and Spatial Strategies, Routledge, Abingdon.

[17]. Kaiser, F.G.; Fuhrer, U., (2003): Ecological behavior's dependency on different forms of knowledge. App. Psychol.: Int. Rev. 52: $598-613$.

[18]. Kisumu Local Interaction Platform (KLIP) (2013): Mistra Urban Futures-Kisumu Local Interaction Platform 3-Day Ecotourism Symposium and Expo Held at Kisumu Museum on $25^{\text {th }}-27^{\text {th }}$ July 2013.

[19]. Ngunyi, R.N (2009): Ecotourism and Sustainable Development in Kenya: a Paper submitted for Ecotourism Final Exam to Sun Yat Sen University.

[20]. Park, J. J., O'Brien, L., Roe, J., Ward Thompson, C., \& Mitchell, R. (2011): The natural outdoors and health: assessing the value and potential contribution of secondary public data sets in the UK to current and future knowledge. Health \& Place .

[21]. Pendleton, L., Martin, L., Webster, D. G., (2000): Public Perceptions of Environmental Quality: A Survey Study of Beach Use and Perceptions in Los Angeles County. University of Southern California.

[22]. Pergams, O.R.W., \& Zaradic, P.A. (2008): Evidence for a fundamental and pervasive shift away from nature-based recreation. Proceedings of the National Academy of Sciences, 105, 2295- 2300.

[23]. Ruane, J.M., (2005): Essentials of Research Methods: A Guide to Social Science Research; Blackwell Publishing.

[24]. Sanderson, I. (2000) 'Evaluation in complex policy systems,' Evaluation, Vol. 6, No. 4, pp. $433-454$.

[25]. Tamas, A. (2000): System Theory in community development. Whitehorse, Yukon and Almonte, Ontario

[26]. The International Ecotourism Society (TIES). (2009): TIES Fact Sheet: Global Ecotourism Facts and Statistics. TIES, Washington, D.C.

[27]. UNEP (2009): Water Security aNd ecosystem services - the critical connection - a contribution to the United Nations World Assessment Programme. UNEP, Nairobi, Kenya.

[28]. UNEP, (2012): United nations Environment Programme. Fresh Water fir the Future; UNEP, Nairobi Programme. P73

[29]. WASPA (2013): Strategic Plan 2013-2017. Water Services Providers Association. Maji House. Nairobi, Kenya.

[30]. Wong, M., Kumar, L., Jenkins, T.M., Xagoraraki, Il, Phanikumar, M.S., \& Rose, J., B., (2009): Evaluation of public health risks at recreational beaches in Lake Michigan via detection od enteric viruses and a human-specific bacteriological marker Water Res. 43.

[31]. Zhang, H. \& Lei, S.L., (2012). A Structural model of residents' intention to participate in ecotourism: The case of a wetland community. Elsevier, Tourism Management, 33, 96-925. 